\title{
Interview with Dr. Faisal Rehman
}

\author{
Joyce Zhang (Meds 2015) and Sissi Cao (Meds 2016) \\ Faculty Reviewer: Dr. Faisal Rehman MD, FRCPC, M.Ed (Department of Medicine, Division of Nephrology)
}

$\mathrm{S}$ tepping into Dr. Faisal Rehman's office, we could not help but notice the countless degrees, teaching awards, photographs and thank-you notes that decorated his walls. On a Friday afternoon, we were lucky to sit down and speak with the distinguished clinician, teacher and boxer at the Schulich School of Medicine \& Dentistry.

As the Nephrology Site Chief and the Director of Internal Medicine clerkship program at University Hospital and chair of the genitourinary block in the first-year curriculum, Dr. Rehman has a longstanding history with Western University. After completing a Bachelors degree in pharmacology at the University of Alberta and a Medical degree at Queen's University, Dr. Rehman began his training in internal medicine at Schulich. He completed his nephrology fellowship in 2001 and went on to pursue a Masters of medical education at the University of Toronto. Dr. Rehman returned to Western University where he has since established a rewarding and successful academic medical career.

Dr. Rehman developed a fascination with medicine at a young age under the influence of family and friends in the profession. He set his mind on internal medicine after exploring clinical observerships but admitted that choosing a specialty was a more difficult challenge than being accepted to medical school. Dr. Rehman recognized near graduation that intellectually stimulation through problem solving was what he enjoyed most in medicine, leading him to choose a residency in internal medicine. Internal medicine's range combined with Dr. Rehman's interest in longitudinal care ultimately drew him to the field of nephrology. He loves nephrology, he tells us, because it involves complicated physiology, offers diversity - from transplants to glomerular nephritis to diabetes - and allows him to help patients in various stages life: from disease in the outpatient clinic to dialysis, to transplant, to transplant failure and return to dialysis.

When asked about the future direction of research in his field, Dr. Rehman says he sees portable artificial kidneys helping restore independence and improve quality of life for the chronic hemodialysis patients he works closely with. He is hopeful new kidney technology could be translated into clinical practice since dialysis is an inconvenience and unpleasant experience for patients. In addition, Dr. Rehman believes that the delivery of care needs to be altered to accommodate the increasing prevalence of chronic kidney disease. "Unless we can have novel inventions like the artificial kidney, I see our dialysis population exploding, I see our CKD (chronic kidney disease) clinics being overwhelmed. Unfortunately disease prevention has not gotten a lot of hype."

As for what he enjoys most about his career, Dr. Rehman's response was strongly echoed by the awards on his walls: "I love to teach," he says, and especially being around students to teach them in the early stages of their careers. In addition to traditional teaching in the classroom, he has served as honorary president of the Hippocratic student council and other class councils. Even his research interests complement medical education. The projects he has overseen have included artificial kidney modeling, training renal fellows and developing nephrologyrelated research filters. In his words, "the best reward is to see a student mature and develop to the point they know more than you. And I've seen that in my students who are now consultants who have really excelled in research or medical education. It makes you proud that you have contributed to that person developing."

We could not leave Dr. Rehman's office without satisfying our curiosity about his charity boxing career that lent him the name King Faisal. Outside of medicine, the physician indulges in boxing, which he enjoyed watching as a child and training in as a youth. When the department needed to raise money for kidney research 5 years ago, Dr. Rehman volunteered to raise money for the Kidney Clinical Research Unit, thinking at the time, "If I'm going to do this, I will do my kind of event." With the help of a friend who was an international boxing champion, the first Knock Out Kidney Disease annual gala was put together in a little over a year in 2008. Not only did Dr. Rehman mastermind the organization of the event, he also trained to fight in the ring in order to raise more money. His initiative and training paid off in a huge way: the event has raised over $\$ 600000$ over the past 4 years for the Kidney Clinical Research Unit and the Mathew Mailing Centre for Transitional Transplant Studies at University Hospital.

Dr. Rehman also shared with us one of his most memorable patients, which was an incredible case of human resilience. This patient was Ms. AL, a single mother of five young children, who suffered from systemic lupus erythematous (SLE) and presented with severe skin rash, hematouria, and proteinuria. Even though her kidney disease of membranous lupus nephritis was initially managed accordingly with immunosuppressants, she started to develop severe hemoptysis secondary to lupus vasculitis of the lungs. She experienced further worsening of kidney function (acute kidney injury) and required multiple transfusions of 20 to 30 units of blood. Any further management of immunosuppression and plasmophoresis just seemed to make matters worse. She had a prolonged hospital stay of 2 months, developed myocarditis and lost a significant amount of weight that severely limited her mobility. But just when the story could not get any worse, the patient suddenly got better. She started to recover after Dr. Rehman stopped one of her immunosuppressive medications. Now, she leads an active and full life, does charity work for a lupus society and is healthy enough to travel all over the world. Dr. Rehman can only speculate that perhaps the powerful immunosuppression meant to control her lupus had essentially functionally ablated her bone marrow as a side effect. It was a memorable case for him because she had been so close to death but then spontaneously got better with no more signs of lupus. He says, "this case helped to reinforce that I need to constantly re-evaluate what I'm doing, and to not stick to a recipe. It 
PROFILES

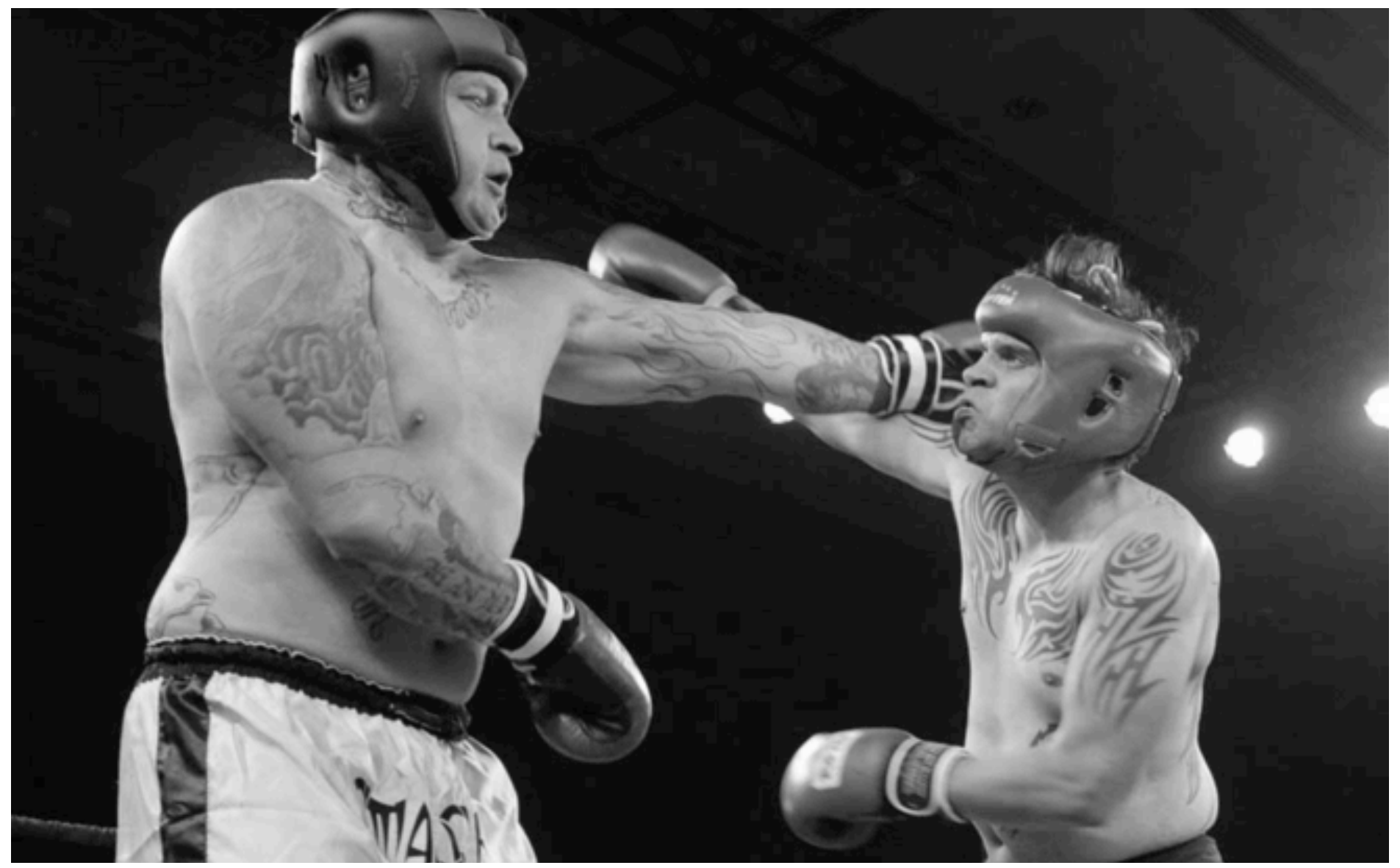

made me realize that medicine is an art for some patients."

For any medical students considering the field of internal medicine and perhaps nephrology, Dr. Rehman has some words of wisdom to offer. "In my opinion nephrologists are the classic internists. They have to know everything about the body," he says. A nephrologist is someone who enjoys complicated physiology and longitudinal care of patients. Nephrologists work in a unique field where patients can never be signed off. They may need to be followed from age 10 to 12 years old until death and everything in between: from dialysis, a transplant, back to dialysis, and through family catastrophe. Lastly, he tells us that, "the first few years of medical school are not conducive to learning about what you want to do when you grow up. What I found helpful is to really maximize the opportunity to do observerships to get a flavour of what's involved to make a better decision. Trying to narrow it down between surgery and medicine upfront may be helpful."

Although many clinicians lead rewarding academic medical careers, few can claim their students know them as King Faisal. Dr. Rehman exemplifies how extensive a physician's involvement in medicine can be. His involvement in patient care, medical education, student initiatives, research and fundraising all reflect his diverse passions and speak to his ability to maintain balance in his life and career. It is clear that Dr. Rehman loves what he does and his patients and students clearly appreciate all the time he gives.

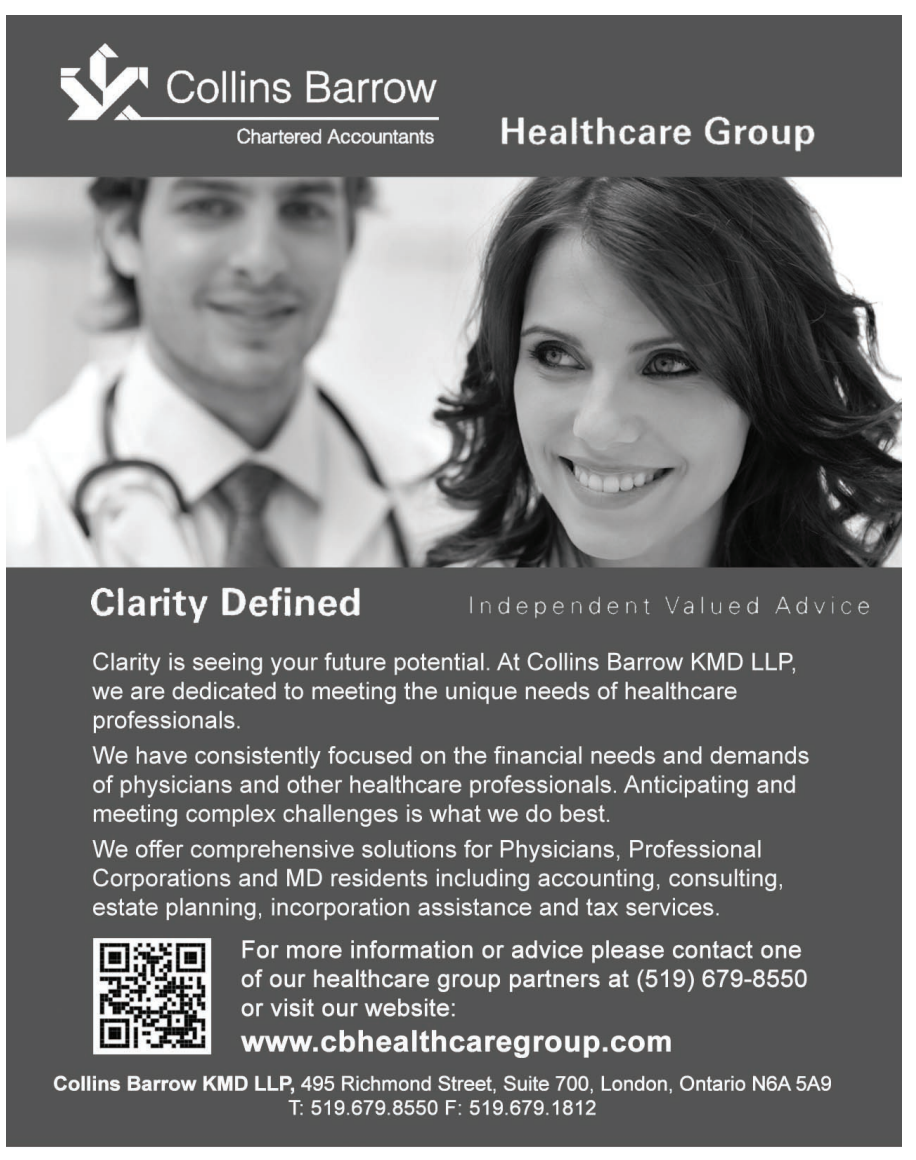

